\title{
Correlación entre los subfactores que conforman la variable apoyo para un sistema de gestión de calidad en una institución educativa
}

Correlation Between the Subfactors that Make Up the Variable Support for a Quality Management System in an Educational Institution

Correlação entre os subfatores que compõem a variável de suporte para um sistema de gestão da qualidade em uma instituição de ensino

Jesús Guillermo Sotelo Asef Universidad Juárez del Estado de Durango, México

chuy_sotelo@hotmail.com https://orcid.org/0000-0002-0560-866X

Sergio Iván López Domínguez Universidad Juárez del Estado de Durango, México ivanlodo1990@hotmail.com https://orcid.org/0000-0001-5764-3160

Ernesto Carreón Gallegos Universidad Juárez del Estado de Durango, México ernestocarreon86@hotmail.com https://orcid.org/0000-0002-2264-9770

Ernesto Geovani Figueroa González Universidad Juárez del Estado de Durango, México geovanifigueroa@yahoo.es https://orcid.org/0000-0002-7900-9141 


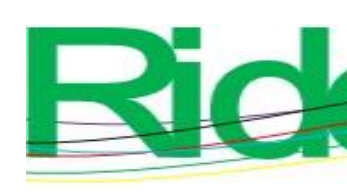

Revista Iberoamericana para la
Investigación y el Desarrollo Educativo
ISSN $2007-7467$

Resumen

Para este estudio el objetivo fue conocer la correlación entre los subfactores que integran los requisitos de apoyo (variable Apoyo) en una institución educativa de nivel superior del estado de Durango, México, y determinar qué relaciones existen entre estos. Los subfactores derivan de los siguientes factores: Recursos, Competencia, Toma de conciencia, Comunicación e Información documentada, todos contenidos en la norma ISO 9001:2015, capítulo siete, "Apoyo o requisitos de apoyo para un sistema de gestión de la calidad", de la Organización Internacional de Normalización (ISO, por sus siglas en inglés). La ruta metodológica que se siguió para cumplir con el objetivo fue a través de un diseño no experimental, de enfoque cuantitativo, con análisis de correlación, descriptivo y de corte transversal. Se aplicó un instrumento, cuyo alfa de Cronbach fue de 0.974, a 400 trabajadores de una institución de educación superior. Entre los resultados, se encontraron 66 (100\%) correlaciones entre los subfactores, y $11(16.7 \%)$ de ellas arrojaron una buena y significativa correlación. Finalmente, se concluye que estas 11 buenas relaciones generan certeza en los requisitos de apoyo y cumplen con los requisitos de apoyo para un sistema de gestión de calidad.

Palabras clave: calidad en el servicio, educación superior, ISO 9001:2015, norma de calidad, requisitos de apoyo.

\section{Abstract}

For this study, the objective was to know the correlation between the sub-factors that make up the support requirements (Support variable) in a higher-level educational institution in the state of Durango, Mexico, and to determine what relationships exist between them. The subfactors are derived from the following factors: Resources, Competence, Awareness, Communication and Documented Information, all contained in the ISO 9001: 2015 standard, clause seven, "Support", of the International Organization for Standardization (ISO). The methodological route followed to meet the objective was through a non-experimental design, with a quantitative approach, with correlation, descriptive and cross-sectional analysis. An instrument, whose Cronbach's alpha was 0.974 , was applied to 400 workers from a higher education institution. Among the results, $66(100 \%)$ correlations were found between the subfactors, and 11 (16.7\%) of them showed a good and significant correlation. Finally, it is concluded that these 11 good relationships generate certainty in the support requirements and meet the support requirements for a quality management system. 


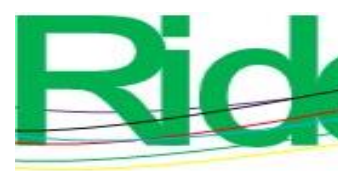

Revista Iberoamericana para la
Investigación y el Desarrollo Educativo
ISSN $2007-7467$

Keywords: quality of service, higher education, ISO 9001:2015, quality standard, support requirements.

\section{Resumo}

Para este estudo, o objetivo foi determinar a correlação entre os subfatores que compõem as necessidades de apoio (variável Apoio) em uma instituição de ensino superior no estado de Durango, México, e determinar quais relações existem entre eles. Os subfatores derivam dos seguintes fatores: Recursos, Competência, Conscientização, Comunicação e Informação Documentada, todos contidos na ISO 9001:2015, capítulo sete, "Requisitos de suporte ou suporte para um sistema de gestão da qualidade", da International Organization for Standardization (ISO). O percurso metodológico seguido para atingir o objetivo foi por meio de um desenho não experimental, com abordagem quantitativa, com análise de correlação, descritiva e transversal. Um instrumento, cujo alfa de Cronbach foi de 0,974 , foi aplicado a 400 trabalhadores de uma instituição de ensino superior. Dentre os resultados, foram encontradas $66(100 \%)$ correlações entre os subfatores, sendo que $11(16,7 \%)$ deles apresentaram correlação boa e significativa. Por fim, conclui-se que essas 11 boas relações geram certeza nos requisitos de suporte e atendem aos requisitos de suporte para um sistema de gestão da qualidade.

Palavras-chave: qualidade de serviço, ensino superior, ISO 9001:2015, padrão de qualidade, requisitos de suporte.

Fecha Recepción: Agosto 2021

Fecha Aceptación: Enero 2022

\section{Introducción}

Para que una organización pública o privada de cualquier sector productivo lleve a cabo sus procesos internos de manera eficiente debe considerar, además de los recursos óptimos, sus propias capacidades y limitantes y poner especial énfasis en aspectos como las personas que integren su estructura, su concientización, los conocimientos y las competencias necesarios para los puestos, su equipamiento y edificios asociados, el ambiente para la operación de sus procesos, los controles e instrumentos de seguimiento y medición, la comunicación interna y externa y toda la información al respecto que se considere útil y necesaria. Así, a partir de la suma de todo lo anterior, poder ofrecer productos o servicios de 


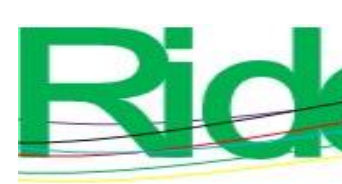

Revista Iberoamericana para la Investigación y el Desarrollo Educativo ISSN $2007-7467$

calidad. En ese sentido, es fundamental evaluar las operaciones de las organizaciones con sistemas de gestión de calidad

Desde el punto de vista de la calidad en los servicios, el estándar de calidad ISO 9001:2015 de la Organización Internacional de Normalización [ISO] (2015a) establece los requisitos necesarios para el soporte, las directrices de seguimiento para implementar y mantener el apoyo para un sistema de gestión de la calidad.

El presente trabajo se desarrolló en una institución de educación superior del estado de Durango. Primeramente, se identificó la variable, a saber, la variable Apoyo, de la que se revisó la literatura y se analizó lo establecido en la norma ISO 9001:2015. Asimismo, se identificaron las dimensiones, factores y subfactores a evaluar. Posteriormente, se procedió a operacionalizar de acuerdo con los puntos que indica la norma ya citada en su cláusula siete. Por último, se realizó un análisis de las correlaciones entre los subfactores.

Para que se proporcione un alto grado de calidad, ya sea en el caso de productos o en el caso de servicios, es de gran relevancia para cualquier organización garantizar la satisfacción final del usuario (interno y externo). Y cuando se habla de conformidad de productos o servicios, es fundamental tener en claro los requisitos de apoyo. Esto otorgará valor agregado a sus procesos. En esa línea, la normatividad ISO 9001:2015 establece los requisitos de apoyo que debe tomar en cuenta cualquier organización. Lo anterior con el objetivo de sustentar las actividades en los sistemas de gestión de calidad, al igual que las diversas herramientas y elementos para llevar a cabo su implementación.

Determinar la correlación entre los elementos de apoyo (subfactores) pondrá al descubierto los elementos que afectan la calidad en el servicio de la institución. Esto mediante la percepción de las personas encargadas de ejecutar las actividades, quienes, cabe señalar, deberán estar guiadas por los objetivos, la mejora continua y la gestión por procesos dentro de la organización. Huelga decir que gestionar los recursos de una manera adecuada traerá como resultado la cohesión entre cada uno de estos.

Así pues, será importante conocer la correlación entre los subfactores que integran los requisitos de apoyo (variable Apoyo) en una institución educativa de nivel superior, de acuerdo con la norma ISO 9001:2015, y poder estar en condiciones de saber qué grado de relación existe entre ellas (muy baja, baja, moderado, buena, muy buena), sin pasar por alto la descripción de dicha relación y su nivel de significancia. 


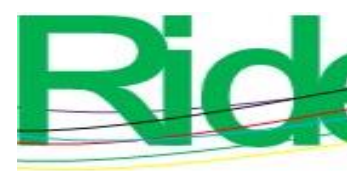

Revista Iberoamericana para la
Investigación y el Desarrollo Educativo
ISSN $2007-7467$

De acuerdo con lo anteriormente mencionado, se deriva la hipótesis siguiente: existe una relación buena y significativa entre los subfactores de la variable Apoyo de acuerdo con la normativa ISO 9001:2015.

Al respecto, esta norma proporciona directrices para establecer un sistema de gestión de calidad. La organización puede hacerse acreedora de una certificación a través de instituciones dedicadas a esto. Sin embargo, contar con certificaciones no necesariamente es sinónimo de calidad en el servicio. De igual manera, los sistemas de gestión de calidad pueden implementarse sin tener como objetivo la certificación; pueden implementarse para generar una cultura de calidad.

Lo relacionado con la variable Apoyo dentro de la norma ISO 9001:2015 se ubica en la cláusula siete. Se trata de un soporte que ayudará a ejecutar los procesos y a brindar recursos humanos, sí, pero también de infraestructura, de ambiente en el que se desarrollan los procesos, así como respecto a aquellos recursos de seguimiento y medición, que darán resultados positivos o negativos según el grado de conformidad con el producto o servicio prestado, de conocimientos de la organización, esto es, todos aquellos aprendizajes que adquiere la organización tanto de manera interna como externa, formal e informal, que se aplican para el logro de los objetivos (ISO, 2015a).

De acuerdo con la estructura de la norma ISO 9001:2015, desarrollada con la metodología del ciclo de planear-hacer-verificar-actuar, también denominado círculo de Deming en honor a su creador, W. Edwards Deming, la variable Apoyo se ubica dentro del cuadrante "hacer", donde se materializa y ejecuta el plan ya establecido, siguiente los requisitos necesarios para este.

Ahondando un poco más en las partes del ciclo de Deming, la fase de "planificar" involucra diversas herramientas que ayudan a identificar aquellas situaciones que no estén alimentando positivamente al sistema de gestión de calidad con la finalidad de tener una mejora; la fase "hacer", como hemos adelantado, conduce a la ejecución de los planes que repercutirán en la mejora; la fase "verificar", como su nombre lo dice, consiste en verificar, revisar, evaluar, entre otras, en el sentido de obtener información que ayude a continuar en el mismo camino o replantearse las acciones que se están llevando a cabo, y en la fase “actuar" se busca propiciar la mejora deseada y comenzar nuevamente a establecer planes de acción (Deming, 1993). 


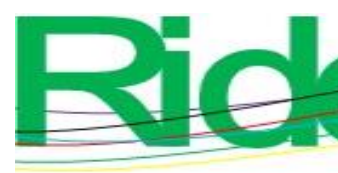

Revista Iberoamericana para la Investigación y el Desarrollo Educativo ISSN $2007-7467$

Ahora bien, los recursos necesarios que establece la ISO 9001:2015 para el apoyo a un sistema de gestión de calidad se conforman de diversos elementos que tanto una organización como el propio sistema deben de tener en cuenta para ejecutar los procesos con responsabilidad, calidad y de manera clara.

De entrada, las personas, principales actores en las organizaciones, aquellas que se encargan de ejecutar las actividades para el logro de los objetivos trazados en común, esto es, el involucramiento desde un nivel estratégico hasta un nivel operativo; en conjunto, forman parte de los recursos necesarios para una organización. Así pues, aquel candidato a ocupar un puesto debe de contar con ciertas características específicas que por la propia naturaleza demanda la organización. El desempeño del personal debe ser efectivo y estar en la disposición de actualizar su conocimiento debido a los cambios vertiginosos presentados en esta era de la globalización (Vesga, 2020).

A su vez, el talento humano es quizá el elemento más importante para lograr la efectividad y, por lo mismo, la organización debe brindarle las herramientas para que los procesos se lleven de manera adecuada. Estas herramientas, por un lado, son la infraestructura, que se integra por los edificios, instalaciones, oficinas, etc., la cual fungirá como el espacio físico donde se realizarán los procesos, así como la totalidad de los activos tangibles e intangibles con los cuales dispone la organización. Por otro lado, existe un uso importante de las tecnologías de la información y comunicación (TIC), equipos de cómputo, desarrollo de software, cuyo objetivo es otorgar seguridad en la información y facilitar, en cierta medida, el trabajo. Paucar, Morales y Altamirano (2017) destacan que los trabajadores, al momento de utilizar estas herramientas, deben contar con el apoyo debido de las áreas de informática tanto como la decisión de la administración estratégica, y lograr así una mayor capacidad de cohesión en la organización.

En sintonía con lo anterior, será importante que se dé énfasis en el ambiente tanto interno como externo en el que se desempeña el individuo; identificar diversos factores en ese contexto como buenos o malos y que a la postre repercuten en la operación de los procesos. Para esto, es importante que en los ambientes donde se desarrollan las actividades se tomen en cuenta tres aspectos: sociales, psicosociales y físicos, los cuales deben ser positivos, es decir, que no haya conflictos entre individuos, prevenir en lo posible el estrés y las emociones negativas, que las áreas sean adecuadas y cuenten con las características mínimas de iluminación, higiene, temperatura, entre otras. 


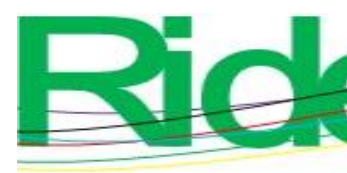

\section{Revista Iberoamericana para la Investigación y el Desarrollo Educativo ISSN 2007 - 7467}

Del mismo modo, para tener un sistema de gestión de calidad que esté en constante retroalimentación y mejora es necesario proporcionar recursos que funcionen como instrumentos de recolección y detección de la satisfacción del usuario —para así poder emprender acciones en la mejora de los servicios o productos-. Asimismo, la organización debe identificar los conocimientos necesarios y ponerlos al alcance de las personas. "Es necesario que estas instituciones produzcan conocimiento, formulen nuevos planteamientos a los requerimientos del ambiente y eso es lo que hace la diferencia" (Lamenta, Aranguren y Canelones, 2019, p. 84). Una organización, en suma, debe preocuparse del conocimiento adquirido tanto por sus fuentes internas como externas.

La competencia, de acuerdo con la ISO 9000:2015, dentro de una organización es vital, por lo que un sistema de gestión de calidad debe contar con personas suficientemente capacitadas, con diversas habilidades y competencias, obtenidas previamente a través de la formación educativa, experiencia laboral. Al mismo tiempo, de forma análoga, la organización debe brindar ciertas herramientas para desarrollarlas. Estos conocimientos funcionarán como mecanismos necesarios para la ejecución de las actividades con responsabilidad, experiencia y calidad (ISO, 2015a). En ese sentido, establecer mecanismos de capacitación es de suma importancia, ya que estos buscan un impacto positivo; la finalidad de estos es aportar un mayor valor a todos los procesos. Al respecto, Sulastri, Gistituati, y Aimon (2021) enfatizan que "la capacitación es un proceso de aprendizaje planificado y guiado con el fin de aumentar los conocimientos, habilidades y actitudes de los trabajadores, tanto individualmente como en grupo" (p. 35). Por supuesto, las capacitaciones y todos estos mecanismos de aprendizaje desarrollados en las organizaciones tienen implicaciones de mejora en la ejecución de los procesos.

Ahora bien, la gestión del conocimiento surge cuando el ámbito educativo y las empresas forman alianzas para fomentar la educación y preparación de aquellos que así lo deseen, proceso que redunda en ventajas competitivas tanto para los empleados como para las organizaciones (Calvo, 2018).

La educación, el compromiso y el sentido de pertenencia ayudan a que se tome conciencia de los objetivos, políticas y de la ejecución correcta de los procesos. De esta manera, la toma de conciencia es parte de la cultura de calidad al interior de la organización. Y según el estándar ISO 9001:2015 esto se "logra cuando las personas entienden sus responsabilidades y cómo sus acciones contribuyen al logro de los objetivos" (ISO, 2015a, p. 3). 


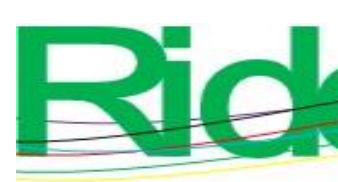

Revista Iberoamericana para la Investigación y el Desarrollo Educativo ISSN $2007-7467$

procesos y consecuentemente hacer los ajustes pertinentes, así como darle cumplimiento a la normatividad. A su vez, toda información que se documenta dentro de un sistema de gestión de calidad y que es utilizada por este es jerarquizada para un entendimiento óptimo, es decir, la información queda estructurada de una manera sencilla con el objetivo de poder ser consultada subsiguientemente. En dicho proceso se define, además, cuál es el mantenimiento que se le debe dar. Aquí puede hacerse uso de un software que contribuya a controlar, manejar y clasificar información documentada de forma electrónica (ISO, 2015a).

Por ende, toda la información que maneje la organización debe contar con un orden o identificación, es decir, como cualquier tipo de archivo, debe tener las fechas correspondientes, los títulos, los formatos de los documentos en los que se va a resguardar, a saber, físico o electrónico. Por un lado, se deben establecer mecanismos de seguridad de la información como parte de la protección de los documentos, ya que se tiene que definir la información delicada, de alta importancia o de menor importancia; así, se pueden identificar y controlar los riesgos. Por otro lado, y de acuerdo con los lineamientos organizacionales y legales, se determinará la vida útil de la información: cuál es la que se almacena y cuál es la que se procede a su destrucción (Díaz y González, 2020).

En efecto, la información documentada debe ser tratada desde dos puntos de vista: de manera interna y externa. Además, cuando sea necesaria cierta información, debe estar disponible, y esta debe ser fiable, es decir, debe ser confiable y auténtica. Aunado a ello, se debe conservar con el objetivo de consultas futuras. Y por último, debe ser accesible para todas las partes interesadas (Cerrillo y Casadesús, 2018).

\section{Materiales y métodos}

El diseño es aquel plan o estrategia que se lleva a cabo para darle cumplimiento a los objetivos de la investigación (Reyes, Reyes y Díaz, 2019). Dentro de este, se establece una ruta a seguir en la que se fijan actividades y pasos con la finalidad de obtener resultados para su posterior análisis.

Para Bernal (2010), los diseños de investigación abren la posibilidad de determinar cuál será el tipo de investigación a llevar a realizar. En este caso, se llevará a cabo una de tipo no experimental, con un enfoque cuantitativo, con análisis de correlación, descriptivo y de tipo transversal, en otras palabras, se llevará a cabo en un solo momento en el tiempo. 


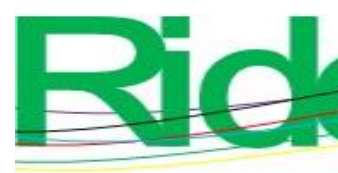

Revista Iberoamericana para la
Investigación y el Desarrollo Educativo
ISSN $2007-7467$

Ahora bien, un análisis de correlación es aquel que se emplea para determinar si existen relaciones entre variables y para entender el comportamiento de estas. En palabras de Roy, Rivas, Pérez y Palacios (2019), "las pruebas de correlación son de utilidad para identificar la tendencia de dos variables a ir juntas, lo que no necesariamente significa que cuando dos variables correlacionan entre ellas sea por una relación de causa y efecto" (p. 360). De esta manera, los índices para identificar una correlación buena positiva o buena negativa van de entre -1 a 1 , es decir, entre más se acerque a 1 o -1 esta tenderá a ser una buena o muy buena correlación entre dos o más variables estudiadas.

Para recabar la información se utilizó un instrumento (tabla 12) conformado por 50 ítems debidamente validado con un alfa de Cronbach de 0.974. La aplicación del instrumento fue a 400 individuos, hombres y mujeres, que se encuentran trabajando en áreas certificadas con la norma ISO 9001:2015. El instrumento presenta el contenido de la variable de estudio y se desglosa de la siguiente manera: cinco factores y 12 subfactores de los cuales emanan los ítems con una escala tipo Likert. Respecto a este punto, Abad, Olea, Ponsoda y García (2011) mencionan que se pueden obtener opiniones, percepciones, rasgos, conductas y actitudes con una escala de medición del grado de aceptación de un enunciado y la frecuencia con que se realiza alguna actividad; otros autores concluyen que para que haya una buena consistencia del instrumento este debe de contar por recomendación con una escala de cinco categorías. Aquí se sigue a Sotelo, Sosa y Carreón (2021), quienes definen las siguientes respuestas: Muy de acuerdo $=5$, De acuerdo $=4$, Indiferente $=3$, En desacuerdo $=2$ y Muy en desacuerdo $=1$. Los resultados se analizaron con el software estadístico SPSS en su versión 23.

\section{Operacionalización de la variable}

Para la operacionalización de la variable es importante que se presente la definición conceptual de cada una de las partes que la integran, con la intención de mostrarla con claridad a todos aquellos interesados en obtener información acerca del estudio, de la variable o del instrumento de medición (Villavicencio, 2019).

Asimismo, esta investigación definió a la variable en las siguientes partes: factores, subfactores, los puntos de la norma a la que hace referencia, su definición conceptual de acuerdo con la norma y los ítems que integran el instrumento utilizado para recolectar la información (tabla 1, 2, 3, 4, 5, 6, 7, 8 y 9). 
Tabla 2. Factor: recursos y sus subfactores

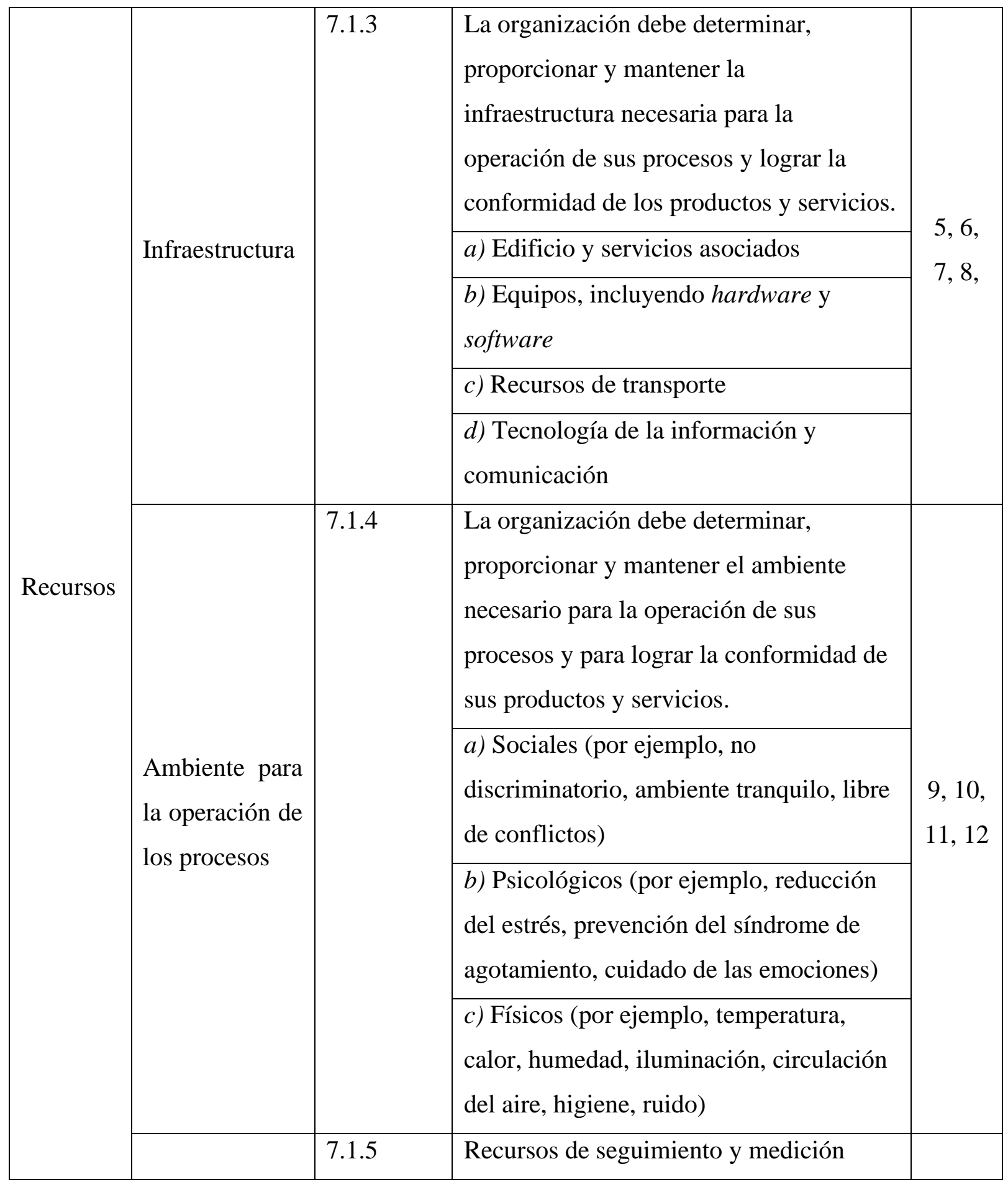

Nota: las definiciones presentadas para la operacionalización de la variable Apoyo son las que establece la norma internacional ISO 9001:2015.

Fuente: Elaboración propia con base en la ISO (2015a) 
Tabla 3. Factor: recursos y sus subfactores

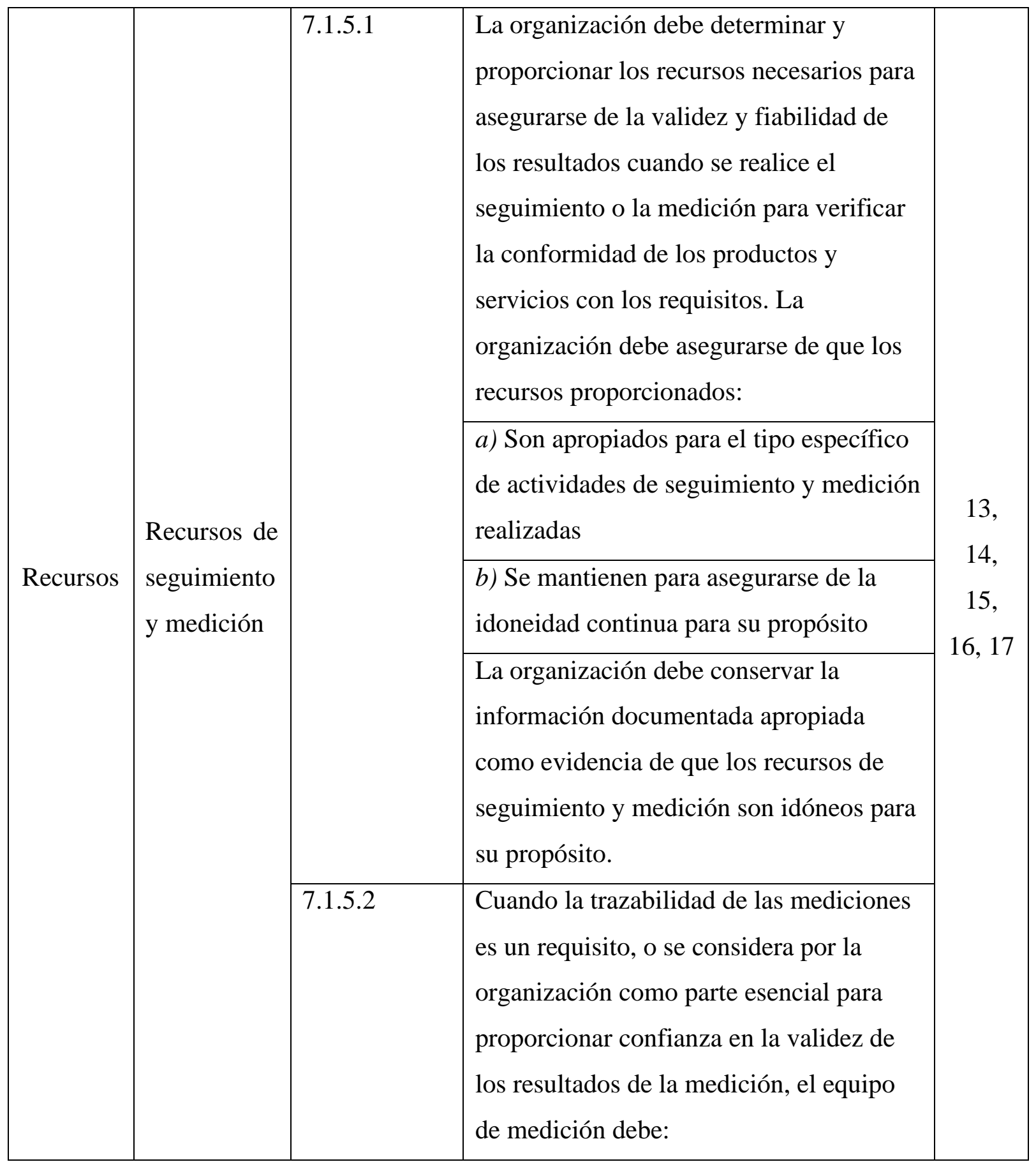

Nota: las definiciones presentadas para la operacionalización de la variable Apoyo son las que establece la norma internacional ISO 9001:2015.

Fuente: Elaboración propia con base en la ISO (2015a) 
Tabla 4. Factor: recursos y sus subfactores

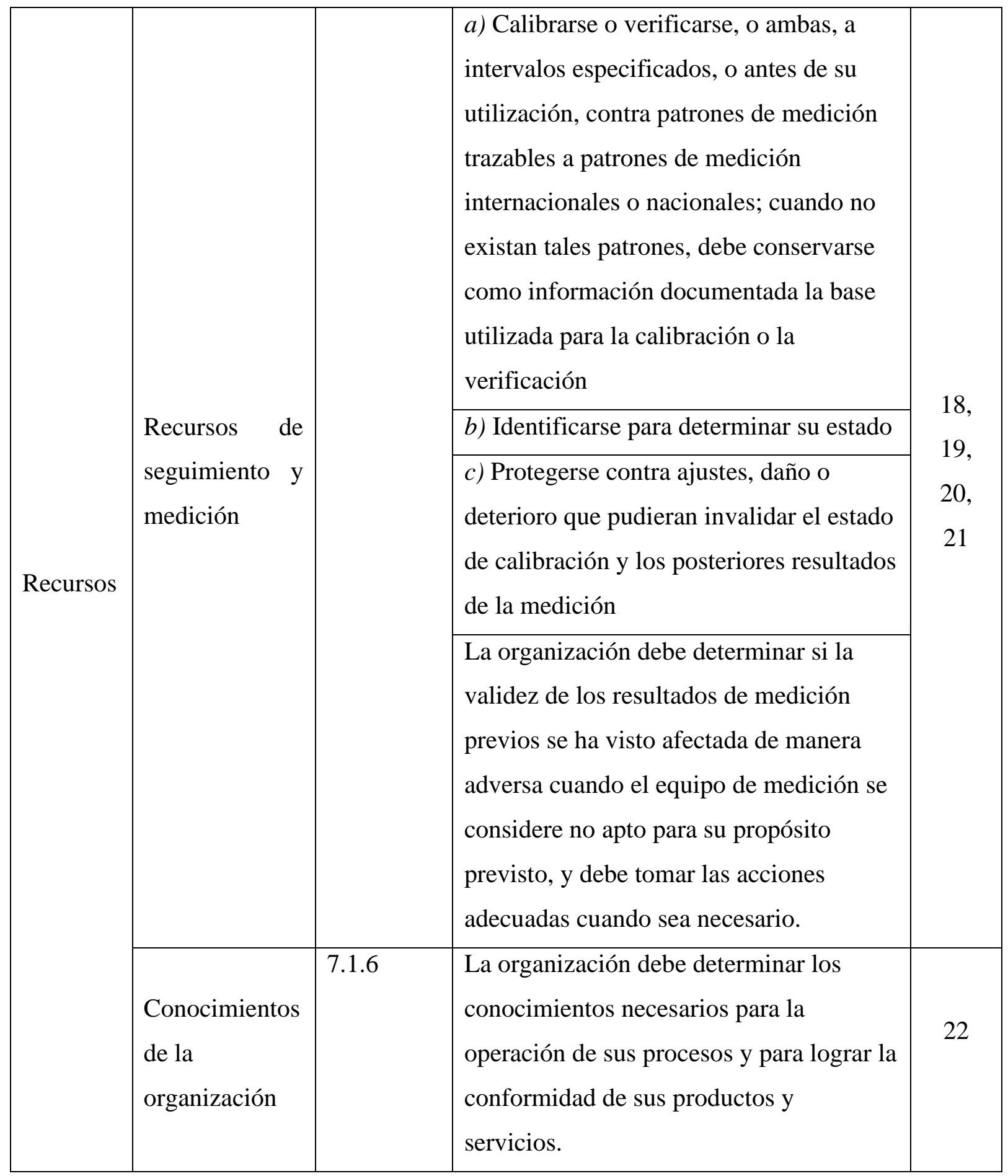

Nota: las definiciones presentadas para la operacionalización de la variable Apoyo son las que establece la norma internacional ISO 9001:2015.

Fuente: Elaboración propia con base en la ISO (2015a) 
Tabla 5. Factor: recursos y sus subfactores

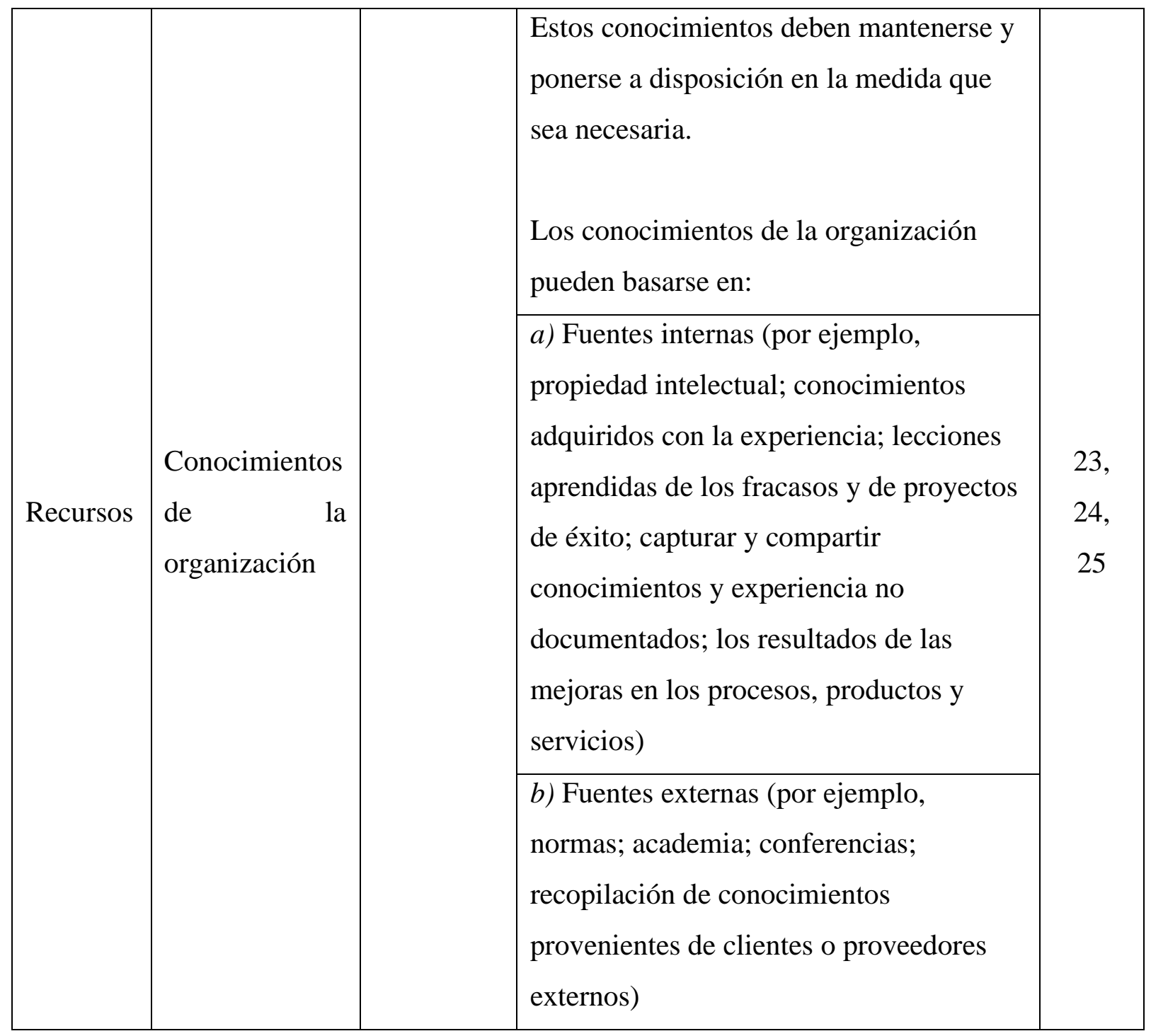

Nota: las definiciones presentadas para la operacionalización de la variable Apoyo son las que establece la norma internacional ISO 9001:2015.

Fuente: Elaboración propia con base en la ISO (2015a) 
Tabla 6. Factor: competencia y sus subfactores

\begin{tabular}{|c|c|c|c|c|}
\hline Factor & Subfactor & $\begin{array}{l}\text { Punto de } \\
\text { la norma }\end{array}$ & Definición & Ítems \\
\hline \multirow{4}{*}{$\begin{array}{l}\text { Compete } \\
\text { ncia }\end{array}$} & \multirow{4}{*}{$\begin{array}{l}\text { Competen } \\
\text { cia }\end{array}$} & \multirow[t]{4}{*}{7.2} & $\begin{array}{l}\text { a) Determinar la competencia necesaria de las } \\
\text { personas que realizan, bajo su control, un } \\
\text { trabajo que afecta al desempeño y eficacia del } \\
\text { sistema de gestión de la calidad }\end{array}$ & \multirow{4}{*}{$\begin{array}{l}26, \\
27, \\
28, \\
29\end{array}$} \\
\hline & & & $\begin{array}{l}\text { b) Asegurarse de que estas personas sean } \\
\text { competentes, basándose en la educación, } \\
\text { formación o experiencia apropiadas }\end{array}$ & \\
\hline & & & $\begin{array}{l}\text { c) Cuando sea aplicable, tomar acciones para } \\
\text { adquirir la competencia necesaria y evaluar la } \\
\text { eficacia de las acciones tomadas }\end{array}$ & \\
\hline & & & $\begin{array}{l}\text { d) Conservar la información documentada } \\
\text { apropiada como evidencia de la competencia }\end{array}$ & \\
\hline
\end{tabular}

Nota: las definiciones presentadas para la operacionalización de la variable Apoyo son las que establece la norma internacional ISO 9001:2015.

Fuente: Elaboración propia con base en la ISO (2015a) 


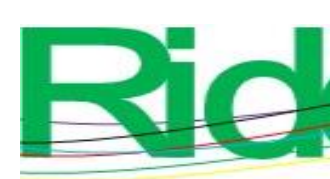

2

Tabla 7. Factor: toma de conciencia y sus subfactores

\begin{tabular}{|c|c|c|c|c|}
\hline Factor & Subfactor & $\begin{array}{l}\text { Punto } \\
\text { de la } \\
\text { norma }\end{array}$ & Definición & Ítems \\
\hline \multirow{5}{*}{$\begin{array}{l}\text { Toma de } \\
\text { conciencia }\end{array}$} & \multirow{5}{*}{$\begin{array}{l}\text { Toma de } \\
\text { conciencia }\end{array}$} & \multirow[t]{5}{*}{7.3} & $\begin{array}{l}\text { La organización debe asegurarse de que todas } \\
\text { las personas que realicen el trabajo bajo el } \\
\text { control de la organización tomen conciencia de: }\end{array}$ & \multirow{5}{*}{$\begin{array}{l}30 \\
31 \\
32 \\
33\end{array}$} \\
\hline & & & a) La política de calidad & \\
\hline & & & b) Los objetivos de la calidad pertinentes & \\
\hline & & & $\begin{array}{l}\text { c) Su contribución a la eficacia del sistema de } \\
\text { gestión de la calidad, incluidos los beneficios } \\
\text { de una mejora del desempeño }\end{array}$ & \\
\hline & & & $\begin{array}{l}\text { d) Las implicaciones del incumplimiento de los } \\
\text { requisitos del sistema de gestión de la calidad }\end{array}$ & \\
\hline
\end{tabular}

Nota: las definiciones presentadas para la operacionalización de la variable Apoyo son las que establece la norma internacional ISO 9001:2015.

Fuente: Elaboración propia con base en la ISO (2015a)

Tabla 8. Factor: comunicación y sus subfactores

\begin{tabular}{|c|c|c|c|c|}
\hline Factor & Subfactor & $\begin{array}{l}\text { Punto de } \\
\text { la norma }\end{array}$ & Definición & Ítems \\
\hline \multirow{6}{*}{ Comunicación } & \multirow{6}{*}{$\begin{array}{c}\text { Comunicació } \\
\mathrm{n}\end{array}$} & 7.4 & $\begin{array}{l}\text { La organización debe determinar las } \\
\text { comunicaciones internas y externas } \\
\text { pertinentes al sistema de gestión de la } \\
\text { calidad, que incluyan: }\end{array}$ & \multirow{6}{*}{$\begin{array}{c}34, \\
35, \\
36, \\
37,38\end{array}$} \\
\hline & & & a) Qué comunicar & \\
\hline & & & b) Cuándo comunicar & \\
\hline & & & c) A quién comunicar & \\
\hline & & & d) Cómo comunicar & \\
\hline & & & e) Quién comunica & \\
\hline
\end{tabular}

Nota: las definiciones presentadas para la operacionalización de la variable Apoyo son las que establece la norma internacional ISO 9001:2015 
Fuente: Elaboración propia con base en la ISO (2015a)

Tabla 9. Factor: información documentada y sus subfactores

\begin{tabular}{|c|c|c|c|c|}
\hline Factor & Subfactor & $\begin{array}{c}\text { Punto de la } \\
\text { norma }\end{array}$ & Definición & Ítems \\
\hline \multirow{9}{*}{$\begin{array}{l}\text { Información } \\
\text { documentada }\end{array}$} & \multirow{3}{*}{ Generalidades } & \multirow[t]{3}{*}{ 7.5.1 } & $\begin{array}{l}\text { El sistema de gestión de la calidad de } \\
\text { la organización debe incluir: }\end{array}$ & \multirow{3}{*}{$\begin{array}{l}39, \\
40\end{array}$} \\
\hline & & & $\begin{array}{l}\text { a) La información documentada } \\
\text { requerida por este proyecto de norma } \\
\text { mexicana }\end{array}$ & \\
\hline & & & $\begin{array}{l}\text { b) La información documentada que } \\
\text { la organización determina como } \\
\text { necesaria para la eficacia del sistema } \\
\text { de gestión de la calidad }\end{array}$ & \\
\hline & \multirow{4}{*}{$\begin{array}{c}\text { Creación y } \\
\text { actualización }\end{array}$} & \multirow[t]{4}{*}{ 7.5.2 } & $\begin{array}{l}\text { Al crear y actualizar la información } \\
\text { documentada, la organización debe } \\
\text { asegurarse de que lo siguiente sea } \\
\text { apropiado: }\end{array}$ & \multirow{4}{*}{$\begin{array}{l}41, \\
42, \\
43\end{array}$} \\
\hline & & & $\begin{array}{l}\text { a) La identificación y descripción } \\
\text { (por ejemplo, título, fecha, autor o } \\
\text { número de referencia) }\end{array}$ & \\
\hline & & & $\begin{array}{l}\text { b) El formato (por ejemplo, idioma, } \\
\text { versión del software, gráficos) y los } \\
\text { medios de soporte ( por ejemplo, } \\
\text { papel, electrónico) }\end{array}$ & \\
\hline & & & $\begin{array}{l}\text { c) La revisión y aprobación con } \\
\text { respecto a la idoneidad y adecuación }\end{array}$ & \\
\hline & \multirow{2}{*}{$\begin{array}{l}\text { Control de la } \\
\text { información } \\
\text { documentada }\end{array}$} & 7.5 .3 & $\begin{array}{l}\text { Control de la información } \\
\text { documentada. }\end{array}$ & \multirow{2}{*}{$\begin{array}{l}44, \\
45, \\
46, \\
47, \\
48,\end{array}$} \\
\hline & & 7.5.3.1 & $\begin{array}{l}\text { La información documentada } \\
\text { requerida por el sistema de gestión de } \\
\text { la calidad y por este proyecto de }\end{array}$ & \\
\hline
\end{tabular}


correlación moderada, de 0.6 a 0.8 una correlación buena y, finalmente, de 0.8 a 1 una correlación muy buena.

Tabla 10. Correlación ro de Spearman entre los subfactores de la variable Apoyo

\begin{tabular}{|c|c|c|c|c|c|c|c|c|c|c|c|c|c|}
\hline & & GR & $\mathrm{P}$ & I & AOP & RSM & $\mathrm{CO}$ & $\mathrm{Ct}$ & TC & Co & GID & $\mathrm{CA}$ & CID \\
\hline \multirow[t]{2}{*}{ GR } & $\begin{array}{l}\text { Coeficiente } \\
\text { de } \\
\text { correlación }\end{array}$ & 1.000 & & & & & & & & & & & \\
\hline & $\begin{array}{l}\text { Sig. } \\
\text { (bilateral) }\end{array}$ & & & & & & & & & & & & \\
\hline \multirow[t]{2}{*}{$\mathrm{P}$} & $\begin{array}{l}\text { Coeficiente } \\
\text { de } \\
\text { correlación }\end{array}$ & $0.476^{* *}$ & 1.000 & & & & & & & & & & \\
\hline & $\begin{array}{l}\text { Sig. } \\
\text { (bilateral) }\end{array}$ & 0.000 & & & & & & & & & & & \\
\hline \multirow[t]{2}{*}{ I } & $\begin{array}{l}\text { Coeficiente } \\
\text { de } \\
\text { correlación }\end{array}$ & $0.187^{* *}$ & $0.572^{* *}$ & 1.000 & & & & & & & & & \\
\hline & $\begin{array}{l}\text { Sig. } \\
\text { (bilateral) }\end{array}$ & 0.000 & 0.000 & & & & & & & & & & \\
\hline \multirow[t]{2}{*}{ AOP } & $\begin{array}{l}\text { Coeficiente } \\
\text { de } \\
\text { correlación }\end{array}$ & $0.109^{*}$ & $0.528^{* * *}$ & $0.616^{\text {*** }}$ & 1.000 & & & & & & & & \\
\hline & $\begin{array}{l}\text { Sig. } \\
\text { (bilateral) }\end{array}$ & 0.029 & 0.000 & 0.000 & & & & & & & & & \\
\hline \multirow[t]{2}{*}{ RSM } & $\begin{array}{l}\text { Coeficiente } \\
\text { de } \\
\text { correlación }\end{array}$ & $0.272^{* *}$ & $0.452^{* *}$ & $0.567^{* *}$ & $0.733^{* *}$ & 1.000 & & & & & & & \\
\hline & $\begin{array}{l}\text { Sig. } \\
\text { (bilateral) }\end{array}$ & 0.000 & 0.000 & 0.000 & .000 & & & & & & & & \\
\hline \multirow[t]{2}{*}{$\mathrm{CO}$} & $\begin{array}{l}\text { Coeficiente } \\
\text { de } \\
\text { correlación }\end{array}$ & 0.088 & $0.380^{* *}$ & $0.443^{* *}$ & $.527^{* *}$ & $.532^{* *}$ & 1.000 & & & & & & \\
\hline & $\begin{array}{l}\text { Sig. } \\
\text { (bilateral) }\end{array}$ & .078 & 0.000 & 0.000 & 0.000 & 0.000 & & & & & & & \\
\hline
\end{tabular}




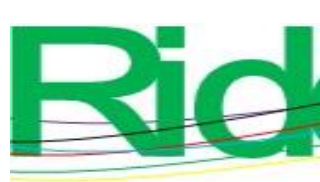

Revista Iberoamericana para la Investigación y el Desarrollo Educativo ISSN 2007 - 7467

\begin{tabular}{|c|c|c|c|c|c|c|c|c|c|c|c|c|c|}
\hline \multirow[t]{2}{*}{$\mathrm{Ct}$} & $\begin{array}{l}\text { Coeficiente } \\
\text { de } \\
\text { correlación }\end{array}$ & -0.067 & $0.459^{* *}$ & $0.596^{* *}$ & $0.639^{* *}$ & $0.685^{* *}$ & $0.415^{* *}$ & 1.000 & & & & & \\
\hline & $\begin{array}{l}\text { Sig. } \\
\text { (bilateral) }\end{array}$ & 0.183 & 0.000 & 0.000 & 0.000 & 0.000 & 0.000 & & & & & & \\
\hline \multirow[t]{2}{*}{$\mathrm{TC}$} & $\begin{array}{l}\text { Coeficiente } \\
\text { de } \\
\text { correlación }\end{array}$ & 0.027 & $0.467^{* *}$ & $0.357^{* *}$ & $0.477^{* *}$ & $0.517^{* *}$ & $0.751^{* *}$ & $0.611^{* *}$ & 1.000 & & & & \\
\hline & $\begin{array}{l}\text { Sig. } \\
\text { (bilateral) }\end{array}$ & 0.596 & 0.000 & 0.000 & 0.000 & 0.000 & 0.000 & 0.000 & & & & & \\
\hline \multirow[t]{2}{*}{ Co } & $\begin{array}{l}\text { Coeficiente } \\
\text { de } \\
\text { correlación }\end{array}$ & $0.188^{* *}$ & $0.541^{* *}$ & $0.351^{* *}$ & $0.404^{* * *}$ & $0.396^{* *}$ & $0.726^{* *}$ & $0.403^{* *}$ & $0.739^{* * *}$ & 1.000 & & & \\
\hline & $\begin{array}{l}\text { Sig. } \\
\text { (bilateral) }\end{array}$ & 0.000 & 0.000 & 0.000 & 0.000 & 0.000 & 0.000 & 0.000 & 0.000 & & & & \\
\hline \multirow[t]{2}{*}{ GID } & $\begin{array}{l}\text { Coeficiente } \\
\text { de } \\
\text { correlación }\end{array}$ & $0.357^{* *}$ & $0.512^{* *}$ & $0.226^{* *}$ & $0.294^{* * *}$ & $0.325^{* *}$ & $0.419^{* *}$ & $0.321^{* *}$ & $0.458^{* * *}$ & $0.489^{* *}$ & 1.000 & & \\
\hline & $\begin{array}{l}\text { Sig. } \\
\text { (bilateral) }\end{array}$ & 0.000 & 0.000 & 0.000 & 0.000 & 0.000 & 0.000 & 0.000 & 0.000 & 0.000 & & & \\
\hline \multirow[t]{2}{*}{ CA } & $\begin{array}{l}\text { Coeficiente } \\
\text { de } \\
\text { correlación }\end{array}$ & $0.461^{* *}$ & $0.492^{* *}$ & $0.258^{* * *}$ & $0.264^{* *}$ & $0.446^{* *}$ & $0.458^{* *}$ & $0.361^{* *}$ & $0.567^{* *}$ & $0.520^{* *}$ & $0.742^{* * *}$ & 1.000 & \\
\hline & $\begin{array}{l}\text { Sig. } \\
\text { (bilateral) }\end{array}$ & 0.000 & 0.000 & 0.000 & 0.000 & 0.000 & 0.000 & 0.000 & 0.000 & 0.000 & 0.000 & & \\
\hline \multirow[t]{2}{*}{ CID } & $\begin{array}{l}\text { Coeficiente } \\
\text { de } \\
\text { correlación }\end{array}$ & $0.164^{* *}$ & $0.526^{* *}$ & $0.549^{* *}$ & $0.439^{* *}$ & $0.559^{* *}$ & $0.513^{* *}$ & $0.558^{* *}$ & $0.646^{* *}$ & $0.597^{* *}$ & $0.550^{* * *}$ & $0.681^{* *}$ & 1.000 \\
\hline & $\begin{array}{l}\text { Sig. } \\
\text { (bilateral) }\end{array}$ & 0.001 & 0.000 & 0.000 & 0.000 & 0.000 & 0.000 & 0.000 & 0.000 & 0.000 & 0.000 & 0.000 & \\
\hline
\end{tabular}

Nota: ${ }^{* *}$ La correlación es muy significativa en el nivel 0.01 (bilateral). ${ }^{*}$ La correlación es significativa en el nivel 0.05 (bilateral). $\mathrm{GR}=$ Generalidades de recursos; $\mathrm{P}=$ Personas; $\mathrm{I}=$ Infraestructura; $\mathrm{AOP}=$ Ambiente para la operación de los procesos; $\mathrm{RSM}=$ Recursos de seguimiento y medición; $\mathrm{CO}=$ Conocimientos de la organización; $\mathrm{Ct}=$ Competencia $; \mathrm{TC}=$ Toma de conciencia; $\mathrm{Co}=$ Comunicación; GID = Generalidades de la información documentada; CA = Creación y actualización, y CID = Control de la información documentada. 


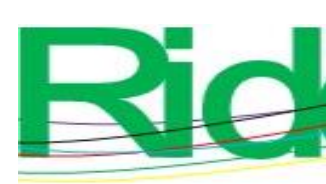

\section{Revista Iberoamericana para la Investigación y el Desarrollo Educativo ISSN $2007-7467$}

Fuente: Elaboración propia

Para continuar, se identificaron que $16.7 \%$ de estas correlaciones entre los subfactores que integran la variable Apoyo muestran que hay correlación buena; en $10.6 \%$ hay correlación muy baja o inexistente (tabla 10).

Tabla 11. Correlaciones identificadas en el análisis

\begin{tabular}{|c|c|c|}
\hline Intervalos & $\begin{array}{c}\text { Cantidad de } \\
\text { correlaciones }\end{array}$ & $\begin{array}{c}\% \\
\text { correlaciones }\end{array}$ \\
\hline $0.0-0.20$ & 7 & $10.6 \%$ \\
\hline $0.21-0.40$ & 15 & $22.7 \%$ \\
\hline $0.41-0.60$ & 33 & $50.0 \%$ \\
\hline $0.61-0.80$ & 11 & $16.7 \%$ \\
\hline $0.81-1.0$ & 0 & $0.0 \%$ \\
\hline Total & 66 & $100 \%$ \\
\hline
\end{tabular}

Nota: los intervalos van de correlación muy baja a correlación muy buena.

Fuente: Elaboración propia

Llaman especialmente la atención los 11 subfactores que cuentan con buena o muy buena relación, de acuerdo con la Tabla 11, así como que su nivel de significancia obtenida asciende a 0.000 ; si es menor a 0.01 , permite afirmar que son muy significativas. Por lo anterior, la competencia guarda una buena relación con recursos de seguimiento y medición (0.685). Igualmente, la competencia presenta una buena relación con la toma de conciencia $(0.685)$.

A su vez, otra buena relación (0.616) es la que se da entre el ambiente para la operación de los procesos con infraestructura. Por un lado, el ambiente para operación de los procesos y los recursos de seguimiento y medición tienen un índice de 0,733 , lo que se traduce en una buena relación. Por otro lado, el ambiente para la operación de los procesos con la competencia presenta también una buena relación (0.639).

Asimismo, la creación y actualización arroja un índice de 0.681 con control de la información documentada, y es una buena relación. Igualmente, las generalidades de información documentada tienen buena relación con creación y actualización (0.742).

También, los conocimientos de la organización con la toma de conciencia tienen buena relación $(0.751)$, los conocimientos de la organización con la comunicación (0.726), 


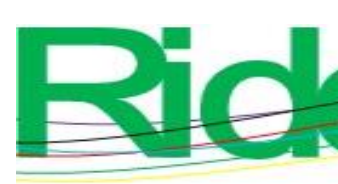

Revista Iberoamericana para la Investigación y el Desarrollo Educativo ISSN $2007-7467$

la toma de conciencia y la comunicación se compaginan de buena manera, por lo que se da una buena relación (0.739), y, por último, la toma de conciencia con control de la información documentada (0.646).

\section{Discusión}

La realización de este estudio de correlación pudo ser capaz de determinar las relaciones que tienen los subfactores de los requisitos de apoyo para un sistema de gestión de calidad que marca la norma ISO 9001:2015. De esta manera, se puede afirmar que la gestión de la calidad y el apoyo son pertinentes para las organizaciones y que el entorno relacionado con el soporte es importante para los operativos y jefes.

Efectivamente, un rasgo importante en este contexto es el estudio del ambiente para operar procesos. Si bien existen situaciones en las que, por el hecho de ser personas con pensamientos distintos, lo natural es que en algún momento se generen situaciones de conflicto, desacuerdos y condiciones de estrés que, en un momento dado, entorpecen los procesos, también estas condiciones son proporcionadas por la organización. Al respecto, Quesada (2019) sostiene que la percepción de un buen ambiente afecta la motivación de las personas, lo que a su vez se ve reflejado directamente en la calidad en los procesos.

Las instituciones de educación superior tienen un compromiso inherente con la gestión del conocimiento y la gestión documental como una decisión estratégica, ya que las exigencias en la actualidad son cada vez mayores. Según García (2017), la gestión del conocimiento se traduce en un factor de ventaja competitiva, lo que impacta en la gestión documental como aquel soporte para darle cumplimiento a los requisitos.

Por último, algunos ejemplos mencionados en párrafos anteriores respecto a la importancia de ciertos requisitos analizados son relevantes para cualquier organización; el efecto positivo de tenerlos en cuenta es observable, la relación que presenta con otros se verá reflejada finalmente en la calidad en el servicio de cualquier institución de educación superior. 


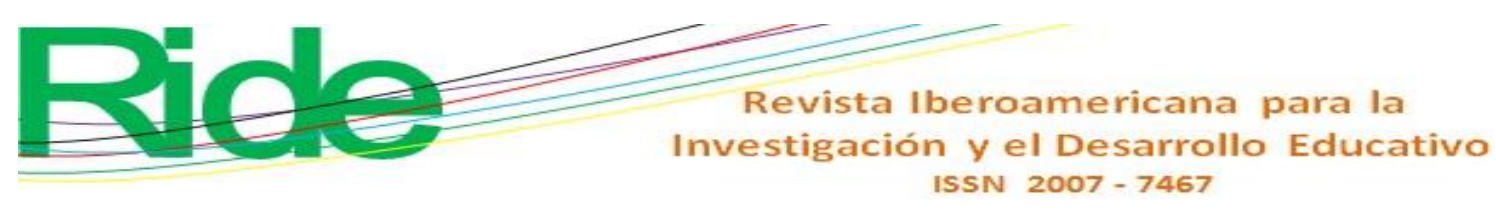

\section{Conclusiones}

El presente trabajo permitió obtener 11 correlaciones positivas entre los subfactores que son parte de los requisitos de apoyo a un sistema de gestión de calidad en una institución de educación. Entre estas se encuentra la toma de conciencia en las personas con la comunicación, ya que el tener bien claro el cumplimiento de actividades, así como el rol de responsabilidades, proporcionará una mejor comunicación entre las áreas de la institución. Otro requisito que pudo ser corroborado y que toma relevancia es la toma de conciencia con el control de la información documentada, donde los individuos tenderán a asumir sus responsabilidades para organizar, distribuir, resguardar y acceder a la información.

Ahora bien, la competencia con la toma de conciencia presenta también una relación. Así, las organizaciones que cuenten con un buen nivel educativo y de capacitación (competencia) tendrán al alcance recursos de seguimiento y medición.

De igual modo, sabemos que los conocimientos de la organización presentan relación con la toma de conciencia. Esto debido a que el acumulado de experiencias internas y externas son transmitidas a sus empleados, lo que genera conciencia al momento de ejecutar los procesos. Otro rasgo que implica a los conocimientos de la organización es que se dé una comunicación efectiva, por lo que existe una relación entre conocimientos de la organización con comunicación.

Por su parte, la creación y actualización en el sentido estricto de organizar los documentos con sus características respectivas de fecha, número de documento, clasificación de los mismos, entre otros, se relaciona con el control de la información documentada, vital para el sistema de gestión de calidad. Por consiguiente, nuevamente la creación y actualización guarda relación con generalidades de la información documentada, ya que cualquier organización debe establecer qué información es relevante, y darle un proceso de conservación y almacenaje.

El ambiente en el que se llevan a cabo los procesos u operaciones de cualquier organización debe ser adecuado, por lo que existe relación con la infraestructura. Por un lado, que existan las condiciones psicológicas, sociales y físicas necesarias para que las personas desempeñen sus actividades; por otro lado, el contar con edificios, tecnología y servicios. Siguiendo con el ambiente para la operación, este guarda relación con los recursos de seguimiento y medición, debido a que un espacio ameno generará las condiciones para realizar con calma sus tareas y establecer los recursos para cumplir con el seguimiento y la 


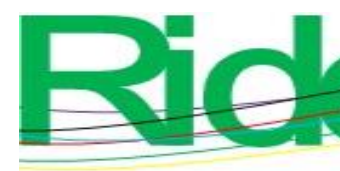

Revista Iberoamericana para la Investigación y el Desarrollo Educativo ISSN $2007-7467$

medición. De igual modo, el desarrollo profesional y el adquirir habilidades es algo que cualquier organización debe proporcionar a sus empleados, lo cual trae beneficios a ambas partes, por lo que el tener un ambiente adecuado para la adquisición y puesta en práctica de estas es fundamental. Y por lo anterior, la competencia tiene relación con el ambiente para la operación de los procesos.

Finalmente, el resto de las 54 correlaciones restantes son capaces de mostrar estadísticamente relación entre ellas, cumpliendo con los requisitos de apoyo para un sistema de gestión de calidad, pero cabe remarcar que son significativas, mas no son buenas, así como también parte de una percepción, donde no todas las personas estarán de acuerdo con un tema. Esto puede provocar que no se logre la suficiente calidad, la cual se refleja hacia el exterior, haciendo énfasis que la calidad hacia los clientes o usuarios es la que define si hay un servicio de calidad o no.

\section{Futuras líneas de investigación}

Este estudio puede seguir en constante crecimiento, ya que su base teórica genera, por un lado, la posibilidad de continuar con posteriores análisis correlacionales entre otros puntos de la norma ISO 9001:2015, así también poder realizar otros análisis con base en metodologías distintas. Por ejemplo, establecer modelos de regresión lineal con la finalidad de encontrar dependencia de un subfactor con otro subfactor de los requisitos de apoyo; lo mismo para dimensión con otra dimensión, factores con factores o subfactores con subfactores del propio contenido de la norma. También, hacer propuestas contrastando otras variables, por ejemplo, la variable calidad en el servicio como tal con los requisitos de apoyo. Los investigadores pueden mostrar interés, tanto de investigación como de utilidad práctica para las organizaciones. Por otro lado, el tema de la calidad, que aporta un gran valor mayormente objetivo a las instituciones que trabajan bajo sistemas de gestión de calidad, ya que las directrices que marca la norma ISO 9001:2015 son claras y precisas para llevarlas a cabo. 


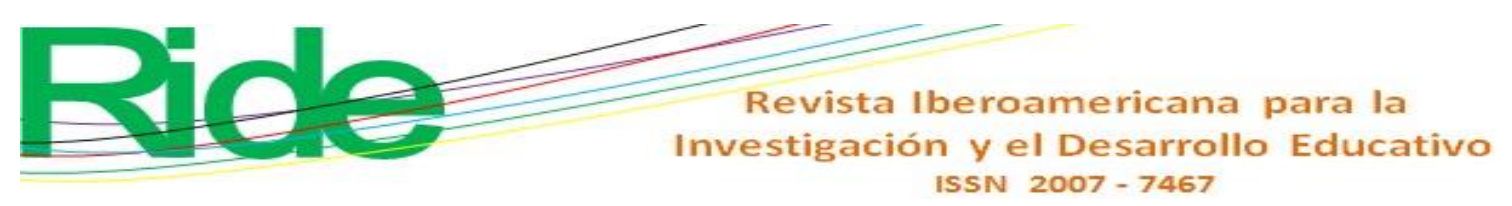

Tabla 12. Instrumento de medición

\begin{tabular}{|c|c|c|c|c|c|c|}
\hline \multicolumn{7}{|c|}{ "Instrumento para medir el apoyo con base en el capítulo siete de la norma ISO 9001:2015". } \\
\hline \multicolumn{7}{|c|}{$\begin{array}{l}\text { Este cuestionario tiene una naturaleza confidencial. Se le solicita cordialmente dar su opinión sobre la veracidad de } \\
\text { los siguientes enunciados según su experiencia en esta institución. Le agradecemos su colaboración. }\end{array}$} \\
\hline \multirow{2}{*}{\multicolumn{7}{|c|}{$\begin{array}{l}\text { Puesto: } \_ \text {Sexo: } \_ \text {Nivel de estudio: } \\
\text { Área: }\end{array}$}} \\
\hline & & & & & & \\
\hline Núm. & Ítem & 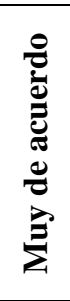 & 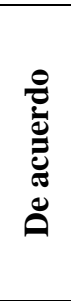 & 离 & 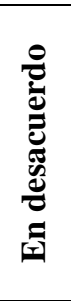 & 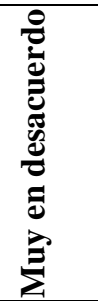 \\
\hline 1 & $\begin{array}{l}\text { Considero que la organización determina y } \\
\text { proporciona los recursos necesarios para el } \\
\text { establecimiento, implementación, mantenimiento y } \\
\text { mejora continua del sistema de gestión de la calidad. }\end{array}$ & & & & & \\
\hline 2 & $\begin{array}{l}\text { Considero que la organización toma en cuenta las } \\
\text { capacidades y limitaciones de los recursos internos } \\
\text { existentes para el establecimiento, implementación, } \\
\text { mantenimiento y mejora continua del sistema de } \\
\text { gestión de la calidad. }\end{array}$ & & & & & \\
\hline 3 & $\begin{array}{l}\text { Considero que la organización toma en cuenta qué se } \\
\text { necesita obtener de los proveedores externos para el } \\
\text { establecimiento, implementación, mantenimiento y } \\
\text { mejora continua del sistema de gestión de la calidad. }\end{array}$ & & & & & \\
\hline 4 & $\begin{array}{l}\text { Considero que la organización determina y } \\
\text { proporciona las personas necesarias para la } \\
\text { implementación eficaz de su sistema de gestión de la } \\
\text { calidad y para la operación y control de sus procesos. }\end{array}$ & & & & & \\
\hline 5 & $\begin{array}{l}\text { Considero que la organización determina, } \\
\text { proporciona y mantiene edificios y servicios } \\
\text { asociados necesarios para la operación de sus } \\
\text { procesos y lograr la conformidad de los productos y } \\
\text { servicios }\end{array}$ & & & & & \\
\hline 6 & $\begin{array}{l}\text { Considero que la organización determina, } \\
\text { proporciona y mantiene equipos, incluyendo } \\
\text { hardware y software necesarios para la operación de }\end{array}$ & & & & & \\
\hline
\end{tabular}




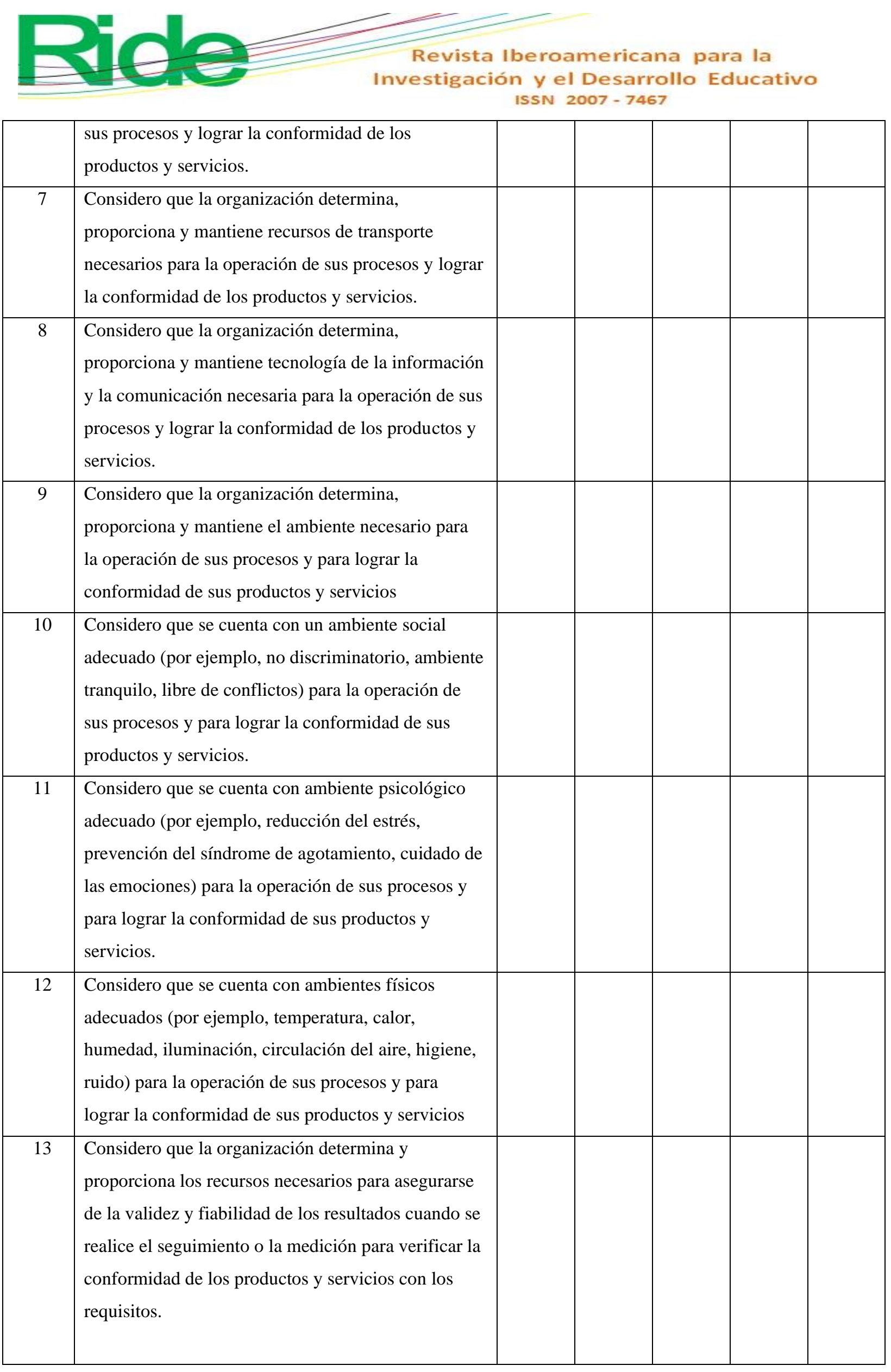




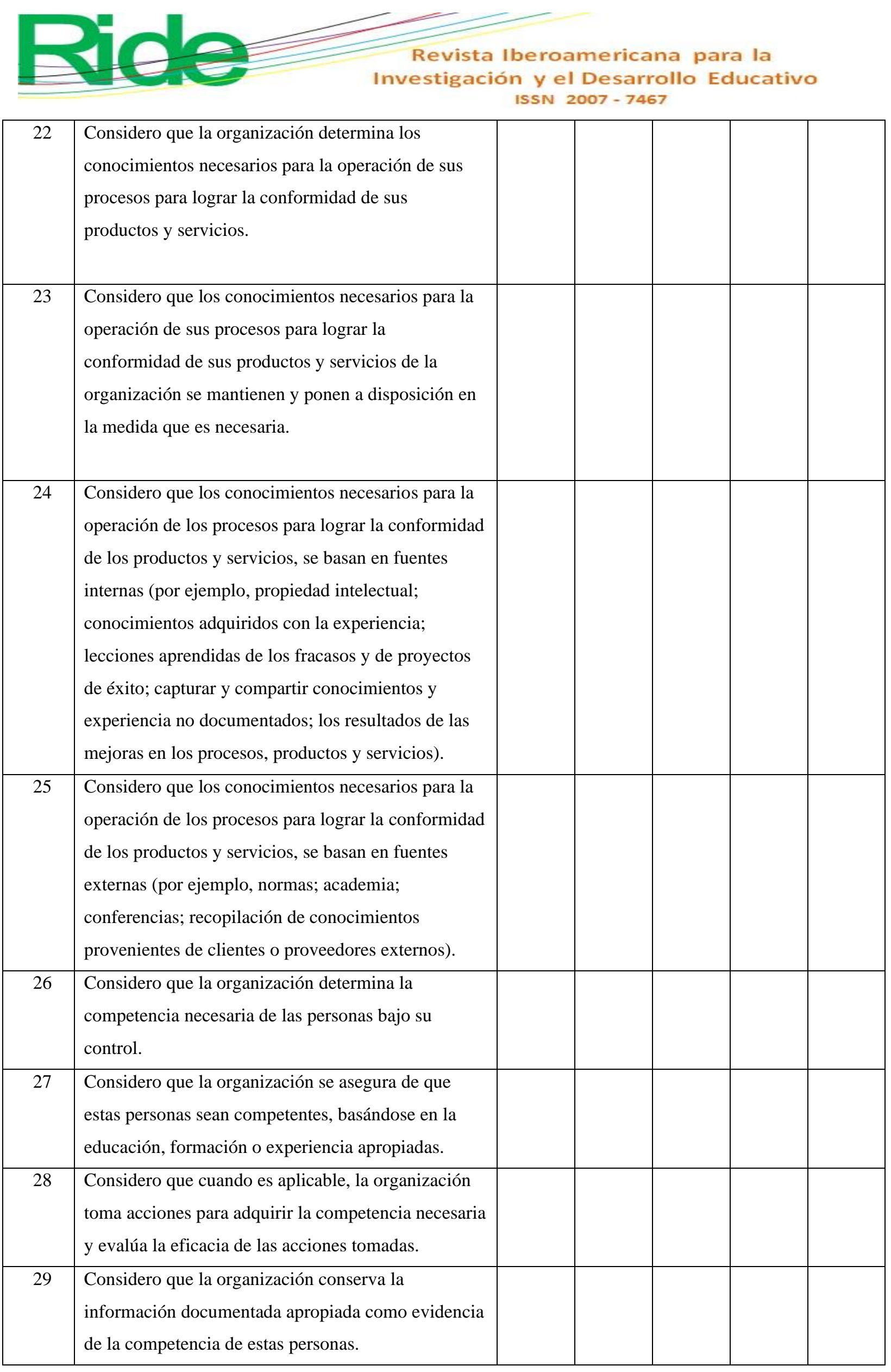




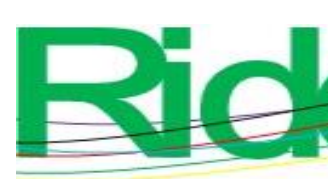

\section{Revista Iberoamericana para la Investigación y el Desarrollo Educativo ISSN 2007 - 7467}

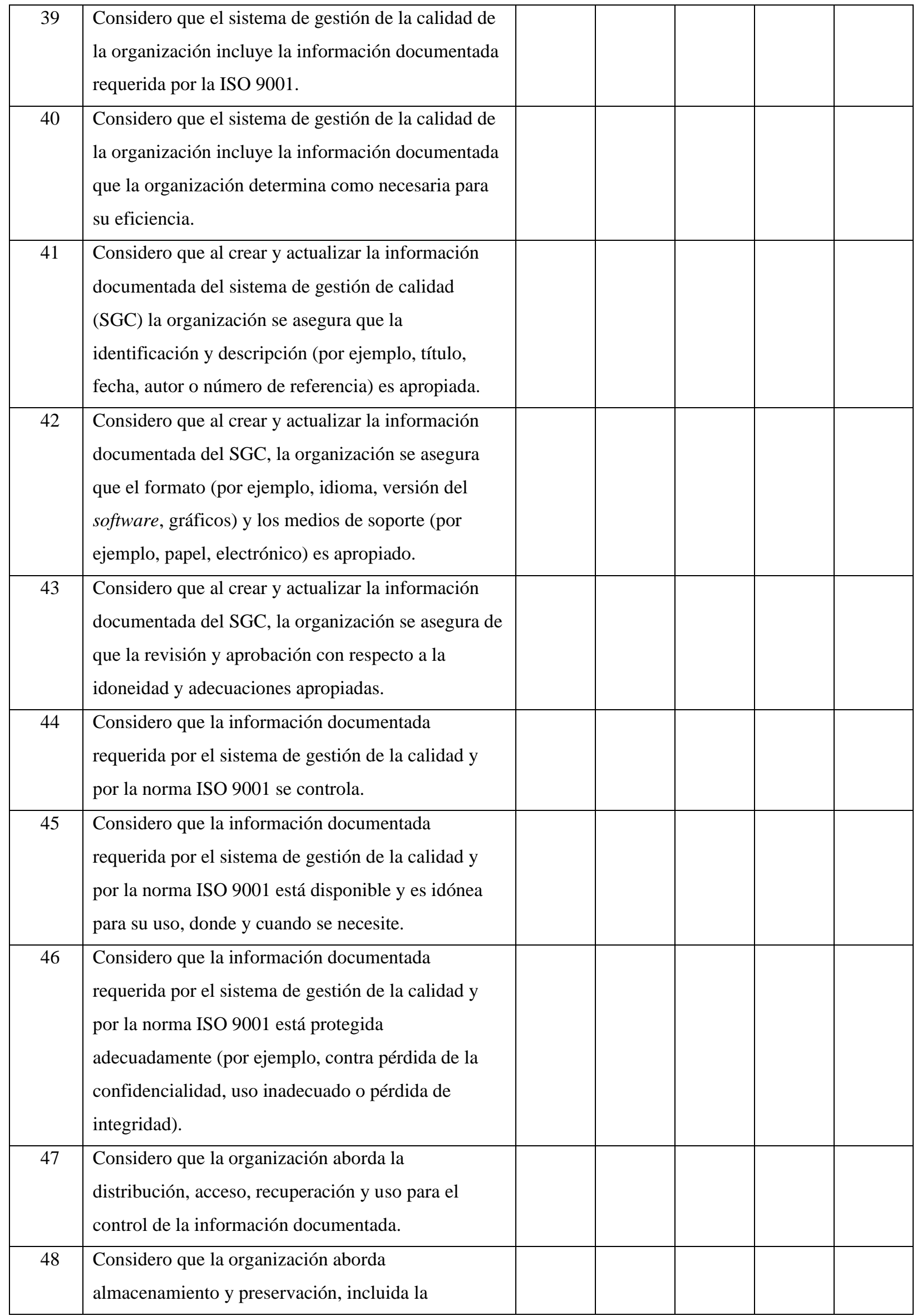




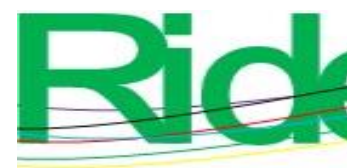

Revista Iberoamericana para la
Investigación y el Desarrollo Educativo
ISSN $2007-7467$

https://www.researchgate.net/publication/350116573_Una_experiencia_de_formaci on_para_futuros_profesores_en_correlacion_y_regresion

Lamenta, P., Aranguren, W. y Canelones, O. (2019). El conocimiento y cambio perpetuo desde las perspectivas de las organizaciones inteligentes. Sapienza Organizacional, 6(11), 75-100. Recuperado de https://www.redalyc.org/journal/5530/553066143005/movil/.

Lipovka, A., Korolyova, N., Nugmanova, M. and Salimzhanova, A. (2021). Comparative influence of gender, age, industry and management level on communication. Problems and Perspectives in Management, 19(2), 170-182. Retrieved from https://www.researchgate.net/publication/351955842_Comparative_influence_of_g ender_age_industry_and_management_level_on_communication_Problems_and_Pe rspectives_in_Management.

Organización Internacional de Normalización [ISO]. (2015a). ISO 9001:2015(es). Sistemas de gestión de la calidad — Requisitos Organización Internacional de Normalización

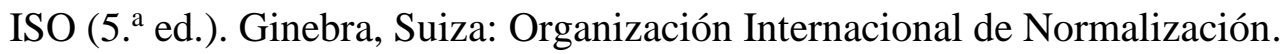

Organización Internacional de Normalización [ISO]. (2015b). ISO 9000:2015(es) Sistemas de gestión de la calidad — Fundamentos y vocabulario. Ginebra, Suiza: Organización Internacional de Normalización.

Paucar, L. M., Morales, J. W. y Altamirano, S. H. (2017). Dirección y gestión estratégica de las TICs. Dominio de las Ciencias, 3(4), 1150-1160.

Pérez, M. (6 de diciembre de 2019). Toma de conciencia del sistema de gestión. Blog Kawak. Recuperado de https://blog.kawak.net/mejorando_sistemas_de_gestion_iso/7.3toma-de-conciencia-del-sgc.

Quesada, Ch. M. J. (2019). Condiciones de la infraestructura educativa en la región pacífico central: los espacios escolares que promueven el aprendizaje en las aulas. Revista Educación, 43(1), 1-19.

Reyes, F., Reyes, A. y Díaz, V. P. (2019). Acerca de los sistemas de clasificación de diseños de investigación en psicología: importancia y alcance. Interciencia, 44(5), 303-309. Recuperado de https://www.redalyc.org/journal/339/33959375009/html/.

Roy, I., Rivas, R., Pérez, M. y Palacios, L. (2019). Correlación: no toda correlación implica causalidad. Revista Alergia México, 66(3) 354-360. Recuperado de http://www.scielo.org.mx/scielo.php?script=sci_arttext\&pid=S244891902019000300354.

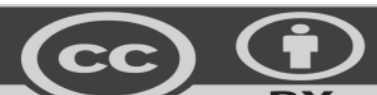



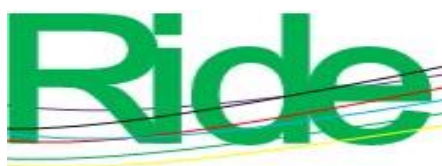

Revista Iberoamericana para la Investigación y el Desarrollo Educativo ISSN $2007-7467$

Sotelo, A. J., Sosa, A. M. y Carreón, G. E. (2021). Medición de la calidad bajo los estándares de la ISO 9001. Validación de instrumentos de acuerdo con la norma ISO 9001:2015. Ciudad de México, México: Pearson.

Sulastri, S., Gistituati, N., S, N. and Aimon, H. (2021). The development of training model in improving administrative leadership competence based on action-based learning in university. Journal of Leadership in Organizations, 3(1), 31-42. Retrieved from https://jurnal.ugm.ac.id/leadership/article/view/63998.

Vesga, J. J. (2020). La gestión de recursos humanos en contextos de individualización. Diversitas: Perspectivas en Psicología, 16(1), 201-213. Recuperado de https://www.redalyc.org/journal/679/67963183015/67963183015.pdf.

Villavicencio, E. (2019). ¿Cómo plantear las variables de una investigación?: operacionalización de las variables. Odontología Activa Revista Científica, 4(1), 914. Recuperado de https://oactiva.ucacue.edu.ec/index.php/oactiva/article/view/289. 


\begin{tabular}{|c|c|}
\hline Rol de Contribución & Autor (es) \\
\hline Conceptualización & Jesús Guillermo Sotelo Asef \\
\hline Metodología & $\begin{array}{l}\text { Jesús Guillermo Sotelo Asef, «igual» Ernesto Geovani Figueroa } \\
\text { González }\end{array}$ \\
\hline Software & No aplica \\
\hline Validación & $\begin{array}{l}\text { Jesús Guillermo Sotelo Asef, «igual» Ernesto Geovani Figueroa } \\
\text { González }\end{array}$ \\
\hline Análisis Formal & $\begin{array}{l}\text { Jesús Guillermo Sotelo Asef, «igual» Ernesto Geovani Figueroa } \\
\text { González }\end{array}$ \\
\hline Investigación & $\begin{array}{l}\text { Sergio Iván López Domínguez, «igual» Ernesto Carreón } \\
\text { Gallegos }\end{array}$ \\
\hline Recursos & $\begin{array}{l}\text { Sergio Iván López Domínguez, «igual» Ernesto Carreón } \\
\text { Gallegos }\end{array}$ \\
\hline Curación de datos & $\begin{array}{l}\text { Jesús Guillermo Sotelo Asef, «principal» Sergio Iván López } \\
\text { Domínguez, «igual» Ernesto Carreón Gallegos «que apoya» }\end{array}$ \\
\hline $\begin{array}{l}\text { Escritura - Preparación del } \\
\text { borrador original }\end{array}$ & $\begin{array}{l}\text { Sergio Iván López Domínguez, «igual» Ernesto Carreón } \\
\text { Gallegos }\end{array}$ \\
\hline Escritura - Revisión y edición & $\begin{array}{l}\text { Sergio Iván López Domínguez, «igual» Ernesto Carreón } \\
\text { Gallegos }\end{array}$ \\
\hline Visualización & $\begin{array}{l}\text { Jesús Guillermo Sotelo Asef, «principal» Sergio Iván López } \\
\text { Domínguez, «igual» Ernesto Carreón Gallegos «que apoya» }\end{array}$ \\
\hline Supervisión & Jesús Guillermo Sotelo Asef \\
\hline Administración de Proyectos & Jesús Guillermo Sotelo Asef \\
\hline Adquisición de fondos & $\begin{array}{l}\text { Jesús Guillermo Sotelo Asef, «igual» Sergio Iván López } \\
\text { Domínguez, «igual» Ernesto Carreón Gallegos, «igual» Ernesto } \\
\text { Geovani Figueroa González }\end{array}$ \\
\hline
\end{tabular}

